\title{
Functional features of hemostasis in physically weakened newborn piglets and calves
}

\author{
Elena $V$. Krapivina $^{1 *}$ and Tatyana $V$. Novikova $^{2}$ \\ ${ }^{1}$ Bryansk State Agricultural University, Kokino village, Vygonichsky district, Bryansk region, 243365, Russia \\ ${ }^{2}$ Vologda State Dairy Farming Academy named after N.V. Vereshchagin, Vologda, 160555, Russia
}

\begin{abstract}
The normal state of hematological parameters in mammals at the beginning of ontogenesis is rightfully considered to be functionally very significant for the development of early ontogenesis in them. Hemostasis is considered to be very significant for vital functions and vulnerable blood systems. Its condition affects trophism due to the effect on the state of microcirculation, which is very important at the beginning of ontogenesis. In the neonatal phase, calves and piglets develop the formation of hemostasis and therefore, during these periods it can be easily disrupted. The appearance of hemostatic dysfunctions in the body of young animals, despite its importance, is still very poorly studied. This circumstance was the motivation for the study of the activity of the hemostatic system in calves and piglets that were born physically weakened. It was found that immediately after birth in weakened calves and piglets, there are physiologically unfavorable changes in platelet activity, vascular hemostasis and blood coagulation. This provides them with the appearance of excessive platelet activity and blood clotting with a significant weakening of vascular hemostasis. All these disorders lead to negative changes in their internal organs and create their serious dysfunctions. The development of disorders in the mechanisms of hemostasis in physically weakened calves and piglets during the neonatal phase is a serious mechanism for weakening their adaptation to the environment and slowing the growth and development of animals.
\end{abstract}

\section{Introduction}

The first stages of ontogenesis are considered very biologically important and at the same time vulnerable in any organism [1]. The normal deployment of an animal organism development program is always determined by the optimum functioning of its nervous system and humoral regulation system [2]. Thorough study of many physiological mechanisms of development of young productive animals and the growth of economically significant parameters in them is of great importance for livestock and pig breeding [3, 4]. For this reason, the search for the best conditions for their life and the leading mechanisms of its conservation is of great importance for basic science [5] and for the cultivation and breeding of any productive animals $[6,7]$.

Earlier studies have confirmed the great importance for maintaining the normal course of the processes of their growth and optimum hematological parameters. The characteristics of hemostasis are of particular functional importance among them [8].

The normal beginning of early ontogenesis and the activity of adaptive mechanisms to environmental factors in calves and piglets is very dependent on hemocirculation in small vessels [9]. Moreover, the course of microcirculation is largely determined by the state of hemostatic mechanisms [10].
The deterioration in the functioning of the mechanisms of hemostasis is often recorded and can weaken the overall viability of the animal. It has been noted that dysfunctions of several hemostasis parameters are often recorded at once [11].

The degree of hemostasis disturbance, especially at a young age, is still poorly studied due to the influence of adverse environmental conditions [12]. In this regard, it is necessary to continue studies on the dynamics of hemostasis in young animals caught in adverse environmental conditions.

The goal was outlined: to assess the dynamics of hemostasis in physically weakened newborn calves and piglets.

\section{Materials and methods}

This work was carried out in full accordance with the ethical standards defined by the European Convention for the Protection of Vertebrate Animals, which are used for experimental and other scientific purposes (adopted in Strasbourg on March 18, 1986 and confirmed in Strasbourg on June 15, 2006).

The work was carried out on physiologically mature physically weakened newborn calves and pigs. They were received from first-calf cows and weakened sows after the first farrowing, which had less body weight at the time of insemination. 
The study included 48 weakened newborn calves (made up the experimental group of calves). All of them were examined and examined once on the 1st day of life. Also 39 physically weakened newborn piglets were examined (constituted the experimental group of piglets). They were also examined once on the 1st day of life. The control in the work was indicators that were obtained during the examination of 42 healthy newborn calves and 35 healthy newborn piglets.

The state of platelet aggregation (AP) was determined by the value of its development time after the introduction of ADP $\left(0.5 \times 10^{-4} \mathrm{M}\right)$ and collagen (1: 2 dilution from the main suspension) into the plasma [13].

The anti-aggregation capabilities of the vascular walls were determined during registration of the time of AP with both inducers in plasma taken without temporary venous occlusion and obtained against its background with the calculation of the value of the index of anti-aggregation activity of the vascular walls. Its value was calculated by dividing the time of AP in plasma taken under conditions of temporary venous stasis by the time of development of AP in standard plasma [13]. The state of vascular control over the hemocoagulation process was determined during the evaluation of antithrombin III activity in standard plasma and in plasma taken using temporary venous occlusion [13]. Then, the index of anticoagulation activity of the vascular walls was calculated. This was done by dividing the value of antithrombin III activity in plasma, which was obtained against the background of venous occlusion in plasma obtained without occlusion [13]. The state of vascular control over fibrinolysis was determined by reducing the duration of spontaneous euglobulin lysis in standard plasma and in plasma, which was obtained under conditions of temporary venous occlusion. The value of the index of fibrinolytic activity of the vascular walls was calculated by dividing the time of euglobulin lysis in standard plasma by the amount of euglobulin lysis in plasma, which was obtained under conditions of temporary venous occlusion [13]

Blood coagulation activity was evaluated by the duration of hemocoagulation during the test of activated partial thromboplastin time, the value of prothrombin time and the value of hemocoagulation time during thrombin time using conventional methods [13]. The obtained results were processed using Student's criterion (td)

\section{Results}

Weakened young animals of both species had a normal platelet count. In calves, AP with collagen attacked for $21.3 \pm 0.19 \mathrm{~s}$, which was $46.5 \%$ less than the control. A comparable acceleration of AP was noted in them with ADP (by $51.5 \%$ ). The time of onset of antibodies with collagen in piglets was accelerated by $52.4 \%$. With ADP, they also developed faster compared to the control by $43.7 \%$ (table 1 ).

In physically weakened calves, weakening of vascular control over antibodies was found: the index of antiaggregation activity of the vessel wall with ADP by
$18.3 \%$, with collagen by $21.2 \%$. In weakened newborn piglets, a decrease in the level of vascular control over AP was revealed: the antiaggregation activity index of the vessel wall was lower than the control with ADP by $12.2 \%$, with collagen by $17.9 \%$.

Depression of synthesis in antithrombin III vessels was found in experimental calves. This was indicated by a decrease in its level in the blood of these animals by $15.1 \%$ and a decrease in the index of anticoagulation activity of the vascular wall by $14.6 \%$. Weakened calves showed inhibition of euglobulin lysis by $26.8 \%$ with a decrease in the index of fibrinolytic activity of blood vessels by $13.6 \%$. Physically weakened piglets showed a low level of antithrombin III activity and a decrease in the anticoagulant activity index of the vascular walls by $13.0 \%$. In experimental piglets, the time of euglobulin lysis was increased by $24.2 \%$, and the index of fibrinolytic activity of the vascular wall was reduced by $13.0 \%$.

The coagulation time in the course of general coagulation tests in experimental calves was accelerated: the value of activated partial thromboplastin time by $27.2 \%$, the value of prothrombin time by $26.9 \%$ and the duration of thrombin time by $14.8 \%$. A similar acceleration of hemocoagulation in coagulation tests was detected in experimental piglets. It turned out that they were characterized by an earlier onset of hemocoagulation in the test of activated partial thromboplastin time by $22.5 \%$, in the test for recording thrombin time by $11.8 \%$ and in the test for determining prothrombin time by $23.1 \%$.

\section{Discussion}

Despite the great biological significance of hemostasis, changes in the activity of its components in functionally weakened calves and piglets are still insufficiently studied. In this regard, it was of theoretical and practical interest to evaluate their state of functional activity of platelets, blood vessels, and the coagulation system. These data should clarify the question of the degree of response of hemostasis to adverse conditions during the intrauterine stage of development of calves and piglets [14].

It becomes clear that in cattle and pigs, the neonatal phase is very vulnerable and, at the same time, functionally significant for further processes of growth, development and laying the foundations for future productivity [15]. It seemed practically significant to assess the degree of change in the functional activity of all elements of the hemostatic system in newborn calves and piglets born weakened. The information obtained should reveal the possible degree of deviation of the components of hemostasis from the optimum in the case of functional weakening of newborn calves and piglets.

The assessment of platelet activity, vascular hemostasis and hemocoagulation in weakened calves and piglets has helped establish the potential level of their changes in these species of productive animals. Obviously, weakened calves and piglets under normal environmental conditions are characterized by activation 
of lipid peroxidation processes in plasma already during the colostrum feeding phase. Apparently, this is due to the development of a weakening of the antioxidant protection of the plasma in them. This leads to the development of damage caused by lipid peroxidation in the external structures of the membranes of platelets and endotheliocytes and its stimulation of the synthesis of coagulation factors in the liver [16].

Table 1. Features of hemostasis in physically weakened newborn calves and piglets

\begin{tabular}{|c|c|c|c|c|}
\hline \multirow{2}{*}{$\begin{array}{l}\text { Registrated } \\
\text { parameters }\end{array}$} & \multicolumn{2}{|c|}{ Newborn calves, $\mathrm{M} \pm \mathrm{m}$} & \multicolumn{2}{|c|}{ Piglets, $\mathrm{M} \pm \mathrm{m}$} \\
\hline & $\begin{array}{l}\text { weakened young, } \\
n=48\end{array}$ & $\begin{array}{c}\text { control group, } \\
n=42\end{array}$ & $\begin{array}{l}\text { weakened young, } \\
n=39\end{array}$ & $\begin{array}{c}\text { control group, } \\
\mathrm{n}=35\end{array}$ \\
\hline Platelet aggregation time with ADP, $\mathrm{s}$ & $26.8 \pm 0.12$ & $\begin{array}{c}40.6 \pm 0.10 \\
p<0.01\end{array}$ & $27.2 \pm 0.14$ & $\begin{array}{c}39.1 \pm 0.16 \\
\mathrm{p}<0.01\end{array}$ \\
\hline Platelet aggregation time with collagen, $\mathrm{s}$ & $21.3 \pm 0.19$ & $\begin{array}{l}31.2 \pm 0.14 \\
\mathrm{p}<0.01\end{array}$ & $20.2 \pm 0.24$ & $\begin{array}{c}30.8 \pm 0.09 \\
\mathrm{p}<0.01\end{array}$ \\
\hline $\begin{array}{l}\text { The value of the index of antiplatelet } \\
\text { activity of the vascular wall with ADP }\end{array}$ & $1.42 \pm 0.17$ & $\begin{array}{c}1.68 \pm 0.13 \\
\mathrm{p}<0.01\end{array}$ & $1.48 \pm 0.19$ & $\begin{array}{c}1.66 \pm 0.17 \\
\mathrm{p}<0.01\end{array}$ \\
\hline $\begin{array}{l}\text { The value of the index of antiaggregatory } \\
\text { activity of the vascular wall with collagen }\end{array}$ & $1.32 \pm 0.07$ & $\begin{array}{c}1.60 \pm 0.08 \\
p<0.01\end{array}$ & $1.34 \pm 0.11$ & $\begin{array}{l}1.58 \pm 0.10 \\
\mathrm{p}<0.01\end{array}$ \\
\hline Activity antithrombin III, \% & $86.7 \pm 0.14$ & $\begin{array}{c}99.8 \pm 0.17 \\
\mathrm{p}<0.01\end{array}$ & $85.6 \pm 0.10$ & $\begin{array}{c}98.6 \pm 0.21 \\
\mathrm{p}<0.01\end{array}$ \\
\hline $\begin{array}{c}\text { Anticoagulant Index Value } \\
\text { vascular wall activity }\end{array}$ & $1.16 \pm 0.06$ & $\begin{array}{l}1.33 \pm 0.07 \\
\mathrm{p}<0.01\end{array}$ & $1.15 \pm 0.09$ & $\begin{array}{c}1.30 \pm 0.05 \\
\mathrm{p}<0.01\end{array}$ \\
\hline $\begin{array}{l}\text { Spontaneous time } \\
\text { euglobulin lysis, min }\end{array}$ & $236.0 \pm 0.42$ & $\begin{array}{c}186.1 \pm 0.41 \\
\mathrm{p}<0.01\end{array}$ & $227.5 \pm 0.54$ & $\begin{array}{c}183.1 \pm 0.32 \\
\mathrm{p}<0.01\end{array}$ \\
\hline $\begin{array}{l}\text { Fibrinolytic index value } \\
\text { vascular wall activity }\end{array}$ & $1.25 \pm 0.06$ & $\begin{array}{l}1.42 \pm 0.16 \\
\mathrm{p}<0.01\end{array}$ & $1.23 \pm 0.09$ & $\begin{array}{l}1.39 \pm 0.12 \\
\mathrm{p}<0.01\end{array}$ \\
\hline Activated partial thromboplastin time, $\mathrm{s}$ & $31.6 \pm 0.16$ & $\begin{array}{c}40.2 \pm 0.30 \\
\mathrm{p}<0.01\end{array}$ & $32.0 \pm 0.28$ & $\begin{array}{c}39.2 \pm 0.24 \\
\mathrm{p}<0.01\end{array}$ \\
\hline Prothrombin time, $\mathrm{s}$ & $14.1 \pm 0.19$ & $\begin{array}{c}17.9 \pm 0.18 \\
\mathrm{p}<0.01\end{array}$ & $14.3 \pm 0.15$ & $\begin{array}{c}17.6 \pm 0.16 \\
\mathrm{p}<0.01\end{array}$ \\
\hline Thrombin time, $\mathrm{s}$ & $16.2 \pm 0.29$ & $\begin{array}{c}18.6 \pm 0.20 \\
\mathrm{p}<0.01\end{array}$ & $16.1 \pm 0.31$ & $\begin{array}{c}18.0 \pm 0.25 \\
\mathrm{p}<0.01\end{array}$ \\
\hline
\end{tabular}

Note: $\mathrm{p}$ - significance of differences in outcome and control, $\mathrm{p}_{1}$ - significance of differences in the dynamics of indicators against the background of correction.

The study has found that weakened calves and piglets throughout the newborn have accelerated platelet aggregation. Obviously, its stability is largely ensured in weakened calves and piglets by increasing the sensitivity of platelet receptors to aggregation inducers constantly present in animal blood and by increasing the activity of platelet mechanisms for the implementation of their functions. The revealed physiological changes can be explained by an increase in the number and sensitivity of the main types of platelet receptors, an increase in the content of adenyl nucleotides in the blood plates, an increase in their secretion during aggregation, an intensification of thromboxane formation and an acceleration of self-assembly of actin and myosin in them [17]. The increase in the sensitivity of blood plates to the action of a strong collagen inducer, found in weakened calves and piglets, is obviously also based on the increase in the functional capabilities of phospholipase C [18]. This leads to their intensification of the phosphoinositol pathway - an increase in the amount of diacylglycerol in platelets and an increase in the activity of protein kinase $\mathrm{C}$, which intensifies the phosphorylation of actin and myosin proteins and accelerates their sliding relative to each other during platelet activation. The increase in the sensitivity of the blood platelets of these animals to a weak inducer of ADP and their binding to fibrinogen via the corresponding receptors (GPIIв-IIIa) is undoubtedly accompanied by the activation of phospholipase $A_{2}$ [19].
This ensured accelerated intake of arachidonate from membrane phospholipids in weakened newborn animals [20], which, under the influence of intensified cyclooxygenase and thromboxanesynthetase, is actively converted in platelets into proaggregated prostaglandins ( $\mathrm{PGF}_{2 \alpha}$ and thromboxane $\mathrm{A}_{2}$ ) [21].

In this regard, it is clear that the level of platelet activity in weakened calves and piglets is excessively increased. This creates obstacles to their normal growth and optimum implementation of their genetic program of productive qualities [22].

Changes in platelet activity in weakened calves and piglets during the neonatal phase were accompanied by functionally disadvantageous violations of vascular control over it. Thus, in weakened animals, a significant decrease in vascular control over platelet activity was revealed due to depression in the synthesis of vascular antiplatelet agents [23]. This was confirmed during a test with temporary venous occlusion in the observed calves and piglets by inhibition of platelet aggregation in response to ADP and collagen [24]. The weakening vascular control of platelets in weakened animals was based on a decrease in the synthesis of prostacyclin and NO in their vessels [25]. This largely contributed to the growth of the density and activity of collagen receptors Ia - IIa and VI on the membranes of blood platelets [26].

In addition, a decrease in the synthesis of substances with anticoagulant (antithrombin III and proteins C and S) and fibrinolytic (tissue plasminogen activator) 
properties is of great importance in weakening the physiologically necessary level of the atrombogenic properties of blood vessels in weakened animals [27]. Obviously, this is due in weakened newborn calves and piglets with a high level of lipid peroxidation in the liquid part of the blood, which leads to alteration of the vascular endothelium and a weakening of the synthesis of hemocoagulation-significant compounds in it.

Based on the studies, it can be argued that in weakened newborn calves and piglets, the activity of vascular hemostasis is significantly reduced, which creates the conditions for incomplete adaptation of animals to living conditions.

Increased hemocoagulation in weakened young animals was associated with an excessive increase in physiological processes characteristic of this age:

1) pronounced activation of a number of factors: V, VIII, IX, XII, which ensured the rapid flow of coagulation along the internal path, as evidenced by the short duration of the activated partial thromboplastin time;

2) significant activity in the blood of animals of factor VII, which ensures physical acceleration of the external coagulation mechanism, as indicated by prothrombin time shortened in them [28].

In addition, the basis of the hypercoagulation found in weakened newborn calves and piglets is apparently based on several more mechanisms: 1) high hypercatecholaminemia at birth, which can stimulate the kinin and thrombin mechanism, as well as the activity of the complement system [29]; 2) plasma levels of angiotensin II, adrenocorticotropic hormone, somatotropic hormone, aldosterone that are able to enhance hemostasis processes at the time of birth; 3) the ingress of a large amount of thromboplastin of tissue origin into the plasma due to excessive alteration of the fragile vessels of the umbilical cord [30].

It becomes clear that under conditions of physical weakening of newborn calves and piglets, excessive activation of hemocoagulation processes takes place, which significantly exceeds the degree of natural physiologically justified changes in their activity at this age.

\section{Conclusion}

Violations of the optimum functioning at the beginning of early ontogenesis inevitably reduces the activity of the body's adaptive mechanisms to environmental factors in calves and piglets. Under these conditions, in animals there is a violation of the hemocirculation process in small vessels, which is largely determined by the state of hemostatic mechanisms in them. In the study, physically weakened newborn calves and piglets showed increased platelet activity, blood clotting, and weakening of vascular hemostasis, which negatively affected their microcirculation. The hemostasiopathy found in these animals caused an increased risk of trophic disturbance in the organs of weakened young animals, which was largely the reason for the inhibition of their growth rate.

\section{References}

1. S.Yu. Zavalishina, Functional Properties Of Coagulation Hemostasis In Calves During The Phase Of Dairy-Vegetative Nutrition, Res. J. of Pharmaceut., Biolog. and Chemical Sci., 9(5), 784-790 (2018)

2. I.N. Medvedev, T.A. Kumova, Valsartan effects on platelet activity in patients with arterial hypertension and metabolic syndrome, Russ. J. of Cardiol., 3, 66-69 (2007)

3. G.S. Mal, N.V. Vorobyeva, A.V. Makhova, I.N. Medvedev, I.I. Fayzullina, Features Of Physical Rehabilitation After Myocardial Infarction, Res. J. of Pharmaceut., Biolog. and Chemical Sci., 9(6), 280-285 (2018)

4. I.N. Medvedev, T.A. Kumova, Angiotensin II receptor inhibitors: role and place in arterial hypertension and metabolic syndrome treatment, Russ. J. of Cardiol., 5, 97-99 (2007)

5. S.Yu. Zavalishina, Functional Activity Of Plasma Hemostasis In Neonatal Calves With Iron Deficiency, Who Received Ferroglucin And Glycopin, Res. J. of Pharmaceut., Biolog. and Chemical Sci., 9(5), 1186-1191 (2018)

6. S.Yu. Zavalishina, Functional Properties Of Anticoagulation And Fibrinolysis In Calves of Plant Nutrition, Res. J. of Pharmaceut., Biolog. and Chemical Sci., 9(5), 1082-1087 (2018)

7. E.S. Tkacheva, S.Yu. Zavalishina, Physiology of Platelet Hemostasis In Piglets During The Phase Of Newborns, Res. J. of Pharmaceut., Biolog. and Chemical Sci., 9(5), 1912-1918 (2018)

8. V.I. Maksimov, S.Yu. Zavalishina, A.V. Parakhnevich, E.N. Klimova, N.A. Garbart, A.A. Zabolotnaya, Yu.I. Kovalev, T.Yu. Nikiforova, E.I. Sizoreva, Physiological Dynamics Of Microrheological Characteristics Of Erythrocytes In Piglets During The Phase Of Milk Nutrition, Res. J. of Pharmaceuti., Biolog. and Chemical Sci., 9(5), 454-459 (2018)

9. T.I. Glagoleva, I.N. Medvedev, Physiological Features Of Anti-aggregational Control Of Blood Vessels Over The Shaped Elements Of Blood In Calves At The Onset Of Ontogenesis, Res. J. of Pharmaceut., Biolog. and Chemical Sci., 9(5), 440-447 (2018)

10. L.V. Korepanova, O.S. Starostina, S.D. Batanov, Blood as an indicator of the interior characteristics of crossbred animals, Zootechny, 10, 26-28 (2015)

11. S.Yu. Zavalishina, Functioning Of Mechanisms Of Hemocoagulation Restriction In Calves At Change Of Methods Of Nutrition, Res. J. of Pharmaceut., Biolog. and Chemical Sci., 9(5), 800-806 (2018)

12. S.Yu. Zavalishina, Functioning Of Platelets In Milk And Vegetable Nutrition Calves, Res. J. of Pharmaceut., Biolog. and Chemical Sci., 9(5), 943-949 (2018)

13. Z.S. Barkagan, A.P. Momot, Diagnosis and controlled therapy of hemostatic disorders (Moscow, 2008) 
14. S.Yu. Zavalishina, Physiology Of Vascular Hemostasis In Newborn Calves, Res. J. of Pharmaceut., Biolog. and Chemical Sci., 9(5), 1037-1044 (2018)

15. S.Yu. Zavalishina, Functional Properties of Hemocoagulation In Calves Of Dairy Nutrition, Res. J. of Pharmaceut., Biolog. and Chemical Sci., 9(5), 1016-1022 (2018)

16. S.Yu. Zavalishina, Deficiency Of Iron As A Cause Of Dysfunction In Calves And Piglets, Res. J. of Pharmaceut., Biolog. and Chemical Sci., 9(5), 978-983 (2018)

17. S.Yu Zavalishina, Functional Antiaggregatory Properties Of Blood Vessels In Calves During Transition From Dairy To Plant Type Of Nutrition, Res. J. of Pharmaceut., Biolog. and Chemical Sci., 9(5), 1110-1116 (2018)

18. S.Yu Zavalishina, Physiological Features of Vascular Hemostasis In Calves of DairyVegetative Food, Res. J. of Pharmaceut., Biolog.1 and Chemical Sci., 9(5), 1137-1143 (2018)

19. S.Yu. Zavalishina, Functional Features of Platelets In Newborn Calves With Iron Deficiency, Res. J. of Pharmaceut., Biolog. and Chemical Sci., 9(5), 1153-1158 (2018)

20. I.N. Medvedev, O.V. Gamolina, Lisinopril effects on platelet activity in patients with arterial hypertension and impaired glucose tolerance, Russ. J. of Cardiol., 3, 45-48 (2008)

21. B.V. Usha, S.Y. Zavalishina, Y.A. Vatnikov, E.V. Kulikov, V.I. Kuznetsov, N.V. Sturov, M.V. Kochneva, A.A. Poddubsky, A.V. Petryaeva, T.I. Glagoleva, Diagnostics of early dysfunctions of anticoagulant and fibrinolytic features of rats' vessels in the course of metabolic syndrome formation with the help of fructose model, Bali Med. J., 8(1), 201-205 (2019)

22. E.S. Tkacheva, S.Yu. Zavalishina, Physiological Aspects Of Platelet Aggregation In Piglets Of Milk Nutrition, Res. J. of Pharmaceut., Biolog. and Chemical Sci., 9(5), 74-80 (2018)
23. N.V. Vorobyeva, G.S. Mal, S.Yu. Zavalishina, T.I. Glagoleva, I.I. Fayzullina, Influence Of Physical Exercise On The Activity Of Brain Processes, Res. J. of Pharmaceut., Biolog. and Chemical Sci., 9(6), 240-244 (2018)

24. Yu. Vatnikov, A. Rudenko, P. Rudenko, Ev. Kulikov, A. Karamyan, V. Lutsay, I. Medvedev, V. Byakhova, E. Krotova, M. Molvhanova, Immuneinflammatory concept of the pathogenesis of chronic heart failure in dogs with dilated cardiomyopathy, Veterinary World, 12(9), 14911498 (2019)

25. S.Yu. Zavalishina, Physiological Features Of Primary Hemostasis In Newborns Calves With Functional Digestive Disorders, Res. J. of Pharmaceut., Biolog. and Chemical Sci., 9(6), 1514-1520 (2018)

26. I.N. Medvedev, Physiological peculiarities of thrombocyte activity of candidates into masters of sports in athletics of preadult age, Bali Med. J., 8(3), 635-639 (2019)

27. S.Yu. Zavalishina, Functional Features Of Hemostasis In Calves Of Dairy And Vegetable Nutrition, Res. J. of Pharmaceut., Biolog. and Chemical Sci., 9(6), 1544-1550 (2018)

28. N.V. Vorobyeva, G.S. Mal, E.V. Skripleva, A.V. Skriplev, T.V. Skoblikova, The Combined Impact Of Amlodipin And Regular Physical Exercises On Platelet And Inflammatory Markers In Patients With Arterial Hypertension, Res. J. of Pharmaceut., Biolog. and Chemical Sci., 9(4), 1186-1192 (2018)

29. S.Yu. Zavalishina, O.N. Makurina, N.V. Vorobyeva, G.S. Mal, T.I. Glagoleva, Physiological Features Of Surface Properties Of The Erythrocyte Membrane In Newborn Piglets, Res. J. of Pharmaceut., Biolog. and Chemical Sci., 9(4), 34-38 (2018)

30. E.S. Tkacheva, S.Yu. Zavalishina, Physiological Features Of Platelet Aggregation In Newborn Piglets, Res. J. of Pharmaceut., Biolog. and Chemical Sci., 9(5), 36-42 (2018) 